\title{
IDENTIFIKASI JENIS DAN PEMANFAATAN TUMBUHAN OBAT DI HUTAN TEMBAWANG OLEH MASYARAKAT KELURAHAN BERINGIN KECAMATAN KAPUAS KABUPATEN SANGGAU
}

\author{
(Identification And Utilization Of Medicinal Plants Of Tembawang Forest By Villagers Of \\ Beringin Village Of Kapuas Subdistrict Of Sanggau Regency)
}

\author{
Khairul Rahman, Evy Wardenaar, Yeni Mariani \\ Fakultas Kehutanan Universitas Tanjungpura Pontianak, Jl. Daya Nasional Pontianak 78124 \\ Email : caul.rahman@yahoo.com
}

\begin{abstract}
This research was carried out in four locations of the Tembawang Forest in Lingkungan Semajau (RW 9), namely Semajau (T1), Tebanan (T2), Sebayur (T3), and Koling (T4). In addition, interviews were also held with people who living near health facilitiy (RW 2), in Beringin Village of Kapuas Subdistrict of Sanggau Regency, West Kalimantan. This research aims to documented the medicinal plants and the knowledge of medicinal plants utilization used by traditional healers and communities of RW 2 and $R W 9$ of Beringin Village. In this research, we found a total of number of 100 medicinal plants species used by traditional healers, and it belonging into 55 families. The most common family is the Zingiberaceae, and tree habitus is the most common habitus found in all four Semajau tembawang forests. The parts of medicinal plants used by the community of Beringin Village are in the form of roots, seeds, fruit, flowers, leaves, bark, fruit skin, rhizomes, tubers, and all parts of medicinal plants. The most common method of processing medicinal plants is boiling, and oral (eat or drink) are the most common administration method.
\end{abstract}

Keywords: Beringin Village, Medicinal Plants, Sanggau Regency, Tembawang Forest, Traditional Knowledge.

\section{PENDAHULUAN}

Hutan tembawang merupakan salah satu bentuk pengelolaan yang dilakukan oleh masyarakat lokal di Kalimantan Barat. Hutan tembawang terbentuk pada areal bekas ladang berpindah, dimana masyarakat lokal menanam berbagai jenis pohon penghasil kayu, buah, getah, dan tanaman obat, sebelum lahan tersebut ditinggalkan. Selain ditanami, banyak juga tumbuhan yang tumbuh secara alami dari proses regenerasi alam. Oleh karena itu hutan tembawang memiliki ekosistem yang unik dengan nilai-nilai yang tinggi baik secara ekonomis maupun nilai konservasi (ITTO, 2011).
Tumbuhan obat pada kawasan hutan tembawang cukup beragam, baik yang sudah dimanfaatkan oleh masyarakat maupun yang belum dimanfaatkan. Pemanfaatan tumbuhan obat tersebut merupakan salah satu bentuk pengetahuan tradisional yang dimiliki masyarakat lokal. Pengetahuan tradisional yang dimiliki setiap suku/etnis dalam memanfaatkan tumbuhan merupakan unsur budaya yang muncul dari pengalaman individu yang disebabkan adanya interaksi dengan lingkungannya dan diwariskan secara turun-temurun yang bertujuan untuk mempertahankan kelangsungan hidup (Nurhaida et al. 2015). 
Kabupaten Sanggau merupakan salah satu Kabupaten yang ada di Provinsi Kalimantan Barat yang masyarakatnya masih memanfaatkan tumbuhan obat untuk mengatasi masalah kesehatan. Pengetahuan masyarakat lokal tentang tumbuhan obat biasanya dimiliki oleh ketua adat, dukun atau praktisi pengobatan tradisonal dan tetua yang berada didalam keluarga. Provinsi Kalimantan Barat adalah wilayah keempat terbesar di Indonesia (26,98\% dari total luas Indonesia) dengan pengalihan fungsi hutan pada tahun 2010 mencapai 9.125.486 hektar (Sardana et al. 2011).

Seiring dengan lajunya degradasi lahan yang terus meningkat setiap tahunnya seperti pembukaan lahan untuk pemukiman, dan perkebunan kelapa sawit menyebabkan terkikisnya plasma nutfah tumbuhan obat yang ada pada hutan tembawang yang belum terindentifikasi. Selain itu pewarisan pengetahuan tentang pemanfaatan tumbuhan obat yang ada pada masyarakat pada umumya hanya dilakukan secara lisan, sehingga informasi pengetahuan tentang pemanfaatan tumbuhan obat tidak terdokumentasi dengan baik menimbulkan kekhawatiran bahwa dimasa depan ilmu pengetahuan ini tidak berkembang dikalangan masyarakat. Modernisasi budaya juga menjadi salah satu sumber masalah yang memacu terjadinya pengikisan pengetahuan tradisional yang dimiliki oleh masyarakat (Bordeker, 2000). Oleh karena itu perlu dilakukan penelitian ini sebagai langkah awal untuk memperoleh informasi mengenai jenis tumbuhan obat pada hutan tembawang Lingkungan Semajau, serta pengetahuan tentang pemanfaatan tumbuhan obat oleh masyarakat Kelurahan Beringin Kecamatan Kapuas Kabupaten Sanggau.

\section{METODE PENELITIAN}

Penelitian ini dilaksanakan di empat lokasi hutan tembawang Lingkungan Semajau (RW 9) Kelurahan Beringin, yaitu hutan tembawang Semajau (T1), Tebanan (T2), Sebayur (T3), dan Koling (T4). Selain itu juga dilakukan wawancara pada masyarakat yang tinggal di dekat fasilitas kesehatan (RW 2) Kelurahan Beringin Kecamatan Kapuas Kabupaten Sanggau Kalimantan Barat (Gambar 1). Penelitian ini dilaksanakan kurang lebih empat minggu efektif di lapangan. Metode yang digunakan dalam penelitian ini adalah wawancara semi struktur dengan teknik snowball sampling dan metode survei untuk mengetahui keanekaragaman spesies tumbuhan obat yang ada pada empat lokasi hutan tembawang Lingkungan Semajau. Pada penelitian ini dilakukan dokumentasi pengetahuan tentang tumbuhan obat oleh responden kunci yang ada di kedua RW Kelurahan Beringin tersebut, kemudian informasi mengenai jenis tumbuhan obat yang didapat ini akan ditanyakan kembali ke masyarakat setempat. Hal ini dilakukan dengan maksud untuk mengetahui apakah pengetahuan tentang pemanfaatan tumbuhan obat oleh responden kunci sudah di transmisikan ke masyarakat setempat. Alat dan bahan yang digunakan adalah alat tulis, herbarium kit, buku atlas tumbuhan obat jilid 1, 2, 3, 4, 5, GPS, kamera, kuisioner, tally sheet, dan tape recorder. Data yang diperoleh berbentuk deskriptif kualitatif dan kuantitatif. Responden umum yang diwawancara sebanyak 25 orang yang 


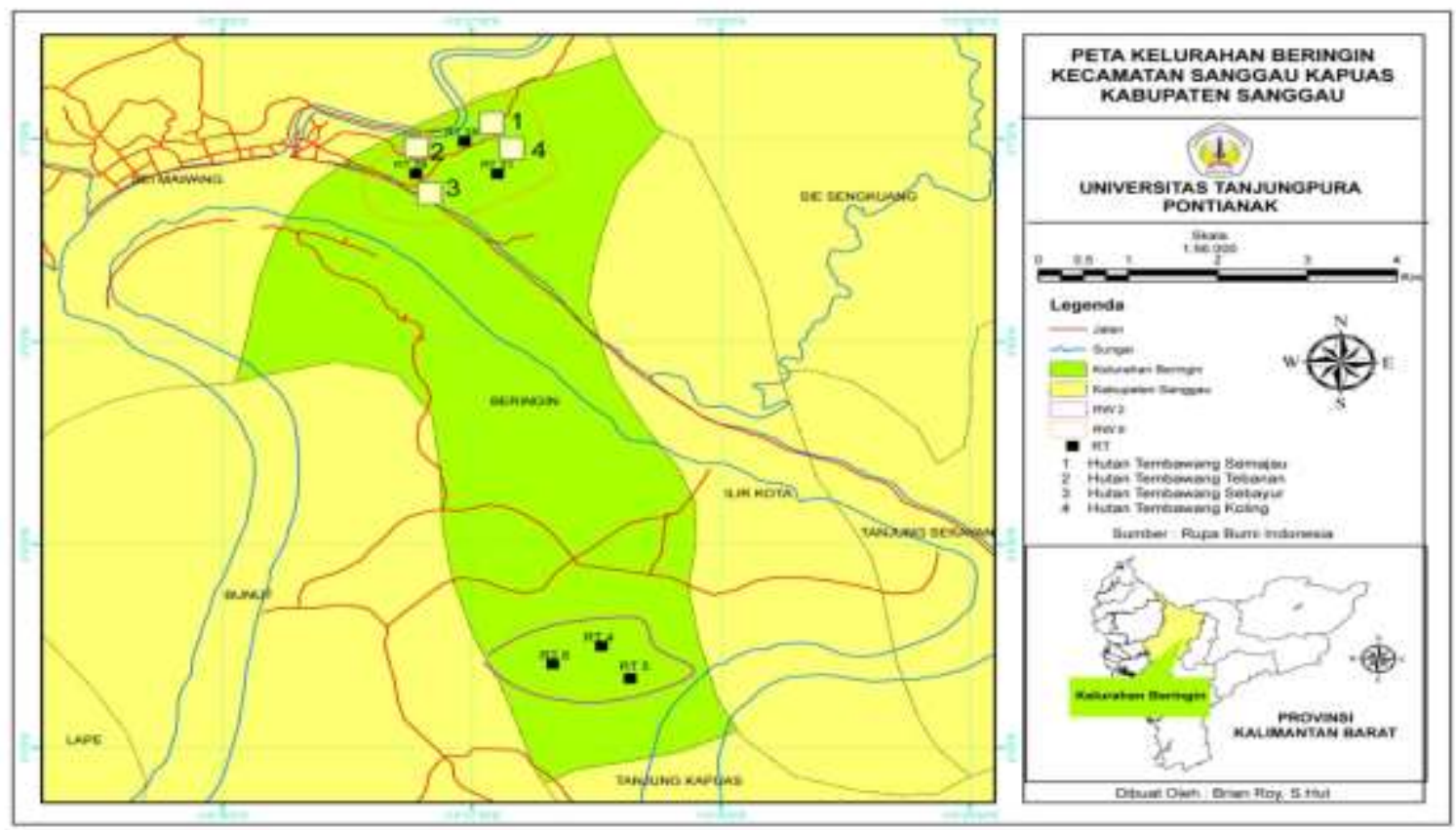

Gambar 1. Peta Lokasi Penelitian (Map Of The Research Location)

HASIL DAN PEMBAHASAN

Pada penelitian ini, dari empat orang responden kunci diperoleh informasi total tumbuhan obat berjumlah 100 jenis yang terdistribusi dalam 55 famili di empat lokasi hutan tembawang Lingkungan Semajau Kelurahan Beringin. Adapun Spesies-spesies tumbuhan yang ditemukan dan dimanfatkan secara lengkap tersaji dalam Tabel 1 (terlampir).

Dari Tabel lampiran dapat dilihat bahwa R1 lebih banyak mengetahui dan memanfaatkan tumbuhan obat yaitu sebanyak 96 spesies (96\%), dan yang paling sedikit adalah masyarakat RW 2 hanya memanfaatkan tumbuhan obat sebanyak 54 spesies saja (54\%). Hal ini diduga dikarenakan sudah hampir 10 tahun R1 berkerja sebagai praktisi pengobatan tradisional, dan pada semasa beliau masih kecil sering mengikuti orang tua ke hutan untuk belajar tanaman obat, sehingga membuat beliau sangat mengetahui tentang tumbuhan obat. Hal ini sejalan dengan penelitian Sari et al.(2015) yang mengatakan bahwa pada umumnya ilmu pengetahuan tentang pemanfaatan tumbuhan obat biasanya diperoleh secara lisan secara turun temurun. Sedangkan masyarakat pada RW 2 disini sudah mengalami perubahan pengetahuan tentang pemanfaatan tumbuhan obat, dimana masyarakat menganggap obat moderen lebih praktis dan hanya menggunakan tumbuhan obat 
disaat pengobatan moderen tidak dapat menyembuhkan penyakit mereka. Hal ini sesuai dengan pernyataan Bordeker (2000), yang mengungkapkan bahwa perubahan pengetahuan lokal, introduksi obat dan pengobatan moderen, pertambahan penduduk, perkembangan ekonomi pasar, dan banyaknya kurangnya generasi muda untuk mempelajari pengetahuan lokal dari leluhurnya, serta banyak generasi tua meninggal dengan tidak mewariskan pengetahuan lokal pada genarasi muda menjadi salah satu sumber masalah yang memacu terjadinya erosi pengetahuan tradisional yang dimiliki oleh masyarakat.

Dari keempat hutan tembawang di Lingkungan Semajau, hutan tembawang Tebanan (T2) memiliki jenis tumbuhan obat yang paling banyak yaitu berjumlah 96 spesies (96\%). Tingginya jenis keanekaragaman jenis tumbuhan di hutan tembawang ini diduga dikarenakan hutan tembawang ini merupakan tembawang pribadi, dimana pemiliknya memiliki kesadaran yang cukup tinggi terhadap budidaya tumbuhan obat. Sebaliknya, hutan tembawang Sebayur yang merupakan hutan tembawang umum dan telah dilakukan alih fungsi lahan pada hutan tembawang ini untuk dijadikan balai betomu, tempat ibadah dan lahan bercocok tanam untuk ibu-ibu PKK menjadi penyebab rendahnya keanekaragaman tumbuhan obat di hutan tersebut (48 species). Hal ini tentu saja dapat menimbulkan keresahan dengan adanya pengalihan lahan hutan tersebut lahan yang sebelumnya penuh dengan keanekaragaman hayati kini mengalami pengikisan serta mengalami kertidak seimbangan ekologi hutan. Penelitian ini sejalan dengan penelitian Sumarhani dan Kalima (2015) yang menyatakan pengalihan fungsi lahan yang terus berkelanjutan akan menimbulkan kekhawatiran, karena menyebabkan hilangnya jenis-jenis tertentu yang akhirnya akan berdampak terhadap penurunan keanekaragaman hayati secara umum yang sangat penting bagi kehidupan.

\section{Tumbuhan Obat Berdasarkan Famili}

Berdasarkan hasil identifikasi di lapangan dari 100 spesies tumbuhan obat yag terdistribusi dalam 55 famili, famili yang paling banyak ditemukan adalah famili Zingiberaceae yaitu sebanyak 7 spesies $(7 \%)$. Kemudian dari 55 famili yang ditemukan ternyata famili Zingiberaceae juga yang paling banyak dimanfaatkan oleh seluruh responden pada penelitian ini, untuk lebih jelasnya dapat dilihat pada Tabel 3. 
JURNAL HUTAN LESTARI (2019)

Vol. 7 (1) : $44-55$

Tabel 3. Pemanfaatan Tumbuhan Obat Berdasarkan Famili ( Number Of Utilization Of Medicinal Plants On It's Family)

\begin{tabular}{|c|c|c|c|c|c|c|c|c|}
\hline \multirow[b]{2}{*}{ No } & \multirow[b]{2}{*}{ Famili } & \multirow{2}{*}{$\begin{array}{c}\text { Spesies } \\
\text { yang } \\
\text { ditemukan } \\
(\%)\end{array}$} & \multicolumn{6}{|c|}{ Spesies yang dimanfaatkan $(\%)$} \\
\hline & & & R1 & $\mathrm{R} 2$ & R3 & R4 & RW 2 & RW 9 \\
\hline 1. & Acanthaceae & 1 & 1 & 1 & 1 & 1 & 1 & 1 \\
\hline 2. & Agavaceae & 2 & 2 & 1 & 2 & 1 & 2 & 2 \\
\hline 3. & Amaranthaceae & 1 & 1 & $*$ & $*$ & $*$ & $*$ & $*$ \\
\hline 4. & Anacardiaceae & 1 & 1 & $*$ & 1 & $*$ & $*$ & 1 \\
\hline 5. & Anisophylleaceae & 1 & 1 & $*$ & $*$ & $*$ & $*$ & $*$ \\
\hline 6. & Annonaceae & 1 & 1 & 1 & 1 & 1 & 1 & 1 \\
\hline 7. & Apiceae & 1 & 1 & 1 & 1 & 1 & 1 & 1 \\
\hline 8. & Apocinaceae & 1 & 1 & $*$ & $*$ & $*$ & $*$ & 1 \\
\hline 9. & Araceae & 3 & 1 & 1 & 1 & 1 & 1 & 1 \\
\hline 10. & Araliaceae & 1 & 1 & 1 & 1 & 1 & 1 & 1 \\
\hline 11. & Arecaceae & 1 & 3 & 2 & 3 & 2 & 2 & 3 \\
\hline 12. & Aspleniaceae & 1 & 1 & $*$ & $*$ & 1 & $*$ & 1 \\
\hline 13. & Asteraceae & 5 & 5 & 2 & 5 & 3 & 2 & 5 \\
\hline 14. & Athyriaceae & 1 & 1 & $*$ & $*$ & $*$ & $*$ & 1 \\
\hline 15. & Bromeliaceae & 1 & 1 & $*$ & 1 & $*$ & 1 & 1 \\
\hline 16. & Cannaceae & 1 & 1 & $*$ & $*$ & $*$ & $*$ & 1 \\
\hline 17. & Caricaceae & 1 & 1 & 1 & 1 & 1 & 1 & 1 \\
\hline 18. & Clusiaceae & 1 & 1 & 1 & 1 & 1 & 2 & 2 \\
\hline 19. & Convolvulaceae & 2 & 1 & 1 & $*$ & $*$ & $*$ & 2 \\
\hline 20. & Crassulaceae & 2 & 1 & 1 & 1 & 1 & 1 & 1 \\
\hline 21. & Cyperaceae & 1 & 1 & $*$ & $*$ & $*$ & $*$ & $*$ \\
\hline 22. & Delliniaceae & 1 & 1 & $*$ & $*$ & $*$ & 1 & 1 \\
\hline 23. & Dicotyledoneae & 1 & 1 & 1 & 1 & 1 & 1 & 1 \\
\hline 24. & Euphorbiaceae & 5 & 5 & 3 & 3 & 2 & 2 & 4 \\
\hline 25. & Fabaceae & 4 & 4 & 1 & 1 & 1 & 1 & 3 \\
\hline 26. & Gleicheniaceae & 1 & 1 & $*$ & $*$ & $*$ & $*$ & 1 \\
\hline 27. & Gnetaceae & 1 & 1 & $*$ & 1 & $*$ & 1 & 1 \\
\hline 28. & Lamiaceae & 1 & 1 & 1 & 1 & 1 & 1 & 1 \\
\hline 29. & Lycopodiaceae & 1 & 1 & 1 & $*$ & $*$ & $*$ & 1 \\
\hline 30. & Malvaceae & 2 & 2 & $*$ & 1 & $*$ & $*$ & 1 \\
\hline 31. & Melastomaceae & 1 & 1 & 1 & 1 & $*$ & 1 & 1 \\
\hline 32. & Meliaceae & 1 & 2 & 1 & 1 & 1 & $*$ & 2 \\
\hline 33. & Menispermaceae & 1 & 1 & 1 & 1 & 1 & 1 & 1 \\
\hline 34. & Mimosaceae & 1 & 1 & $*$ & 1 & $*$ & $*$ & $*$ \\
\hline 35. & Moraceae & 4 & 4 & $*$ & 1 & $*$ & $*$ & 2 \\
\hline 36. & Musaceae & 1 & 1 & 1 & 1 & 1 & 1 & 1 \\
\hline 37. & Myrtaceae & 1 & 3 & 3 & 3 & 3 & 3 & 3 \\
\hline 38. & Naphenthaceae & 3 & 1 & 1 & 1 & 1 & 1 & 1 \\
\hline 39. & Oleaceae & 1 & 1 & $*$ & 1 & $*$ & 1 & 1 \\
\hline 40. & Oxalidaceae & 3 & 2 & 1 & 3 & 2 & $*$ & 2 \\
\hline 41. & Pandanaceae & 1 & 1 & 1 & 1 & 1 & 1 & 1 \\
\hline 42. & Passifloraceae & 1 & 1 & $*$ & $*$ & $*$ & $*$ & 1 \\
\hline 43. & Phyllanthaceae & 1 & 1 & 1 & 1 & 1 & 1 & 1 \\
\hline 44. & Piperaceae & 1 & 2 & 1 & 1 & 2 & 1 & 2 \\
\hline 45. & Poaceae & 6 & 6 & 2 & 2 & 2 & 2 & 5 \\
\hline 46. & Polypodiaceae & 1 & 2 & 1 & $*$ & $*$ & 2 & 2 \\
\hline 47. & Rubiaceae & 4 & 4 & 3 & 4 & 4 & 4 & 4 \\
\hline 48. & Rutaceae & 3 & 2 & 2 & 3 & 2 & 2 & 2 \\
\hline 49. & Sapindales & 1 & 1 & 1 & $*$ & 1 & $*$ & $*$ \\
\hline
\end{tabular}




\begin{tabular}{lcccccccc} 
50. & Sapotaceae & 1 & $*$ & $*$ & 1 & 1 & 1 & $*$ \\
51. & Schizaceae & 1 & 1 & $*$ & $*$ & $*$ & $*$ & 1 \\
52. & Solanaceae & 2 & 2 & 1 & 1 & 1 & 1 & 2 \\
53. & Thymelaeaceae & 1 & 1 & $*$ & $*$ & $*$ & $*$ & $*$ \\
54. & Verbenaceae & 3 & 3 & 3 & 2 & 2 & 3 & 3 \\
55. & Zingiberaceae & 7 & 7 & 7 & 6 & 6 & 5 & 7 \\
\hline & Total Spesies & 100 & 96 & 54 & 64 & 52 & 54 & 85 \\
\hline
\end{tabular}

Keterangan $=^{*}:$ Belum Dimanfaatkan, R1 $=$ Responden Kunci 1, R2 $=$ Responden Kunci 2, R3 = Responden Kunci 3, R4 = Responden Kunci 4. RW 2 = Masyarakat pad RW 2, RW 9 = Masyarakat pada RW 9

Dari Gambar 2, dan Tabel 3 diatas dapat dilihat bahwa dari jumlah total 100 spesies tumbuhan obat yang terdistribusi dalam 55 famili, famili Zingiberaceae lebih banyak ditemukan dan dimanfaatkan oleh responden kunci maupun responden umum. Hal ini dikarenakan famili Zingiberaceae lebih mudah didapat karna mudah tumbuh di berbagai habitat. Sedangkan famili yang paling sedikit ditemukan dikarenakan hanya 1 spesies saja yang diketahui manfaatnya. Hal ini sejalan dengan penelitian Warida et al. (2016) yang mengatakan bahwa pada umumnya masyarakat banyak menanam tumbuhan yang berasal dari famili Zingiberaceae karena mudah tumbuh diberbagai habitat, misalnya cekur ( $K$. galanga), selain sebagai penyembuh penyakit masyarakat juga memanfaatkannya sebagai bumbu dapur.

\section{Tumbuhan Obat Berdasarkan Habitus}

Pada penelitian ini dari total 100 tumbuhan obat yang ditemukan di empat hutan tembawang Lingkungan Semajau, jika tumbuhan obat dilihat berdasarkan habitusnya mulai dari epifit, herba, liana, perdu, pohon, dan semak. Habitus yang paling banyak ditemukan pada T1 dan T2 yaitu habitus pohon sebanyak 29 spesies (29\%) dan 32 spesies (32\%), sedangkan pada T3 dan T4 ternyata habitus herba yang lebih banyak ditemukan yaitu 25 spesies (25\%) dan 26 spesies (26\%). Adapun habitus yang paling sedikit ditemukan pada keempat hutan tembawang tersebut adalah berasal dari habitus epifit yaitu 3 spesies (3\%) pada T1, 2 spesies (2\%) pada T2, T3, dan T4. Untuk perbandingan habitus pada keempat hutan tembawang Lingkungan Semajau tersebut dapat dilihat pada Gambar 2 dibawah ini. 


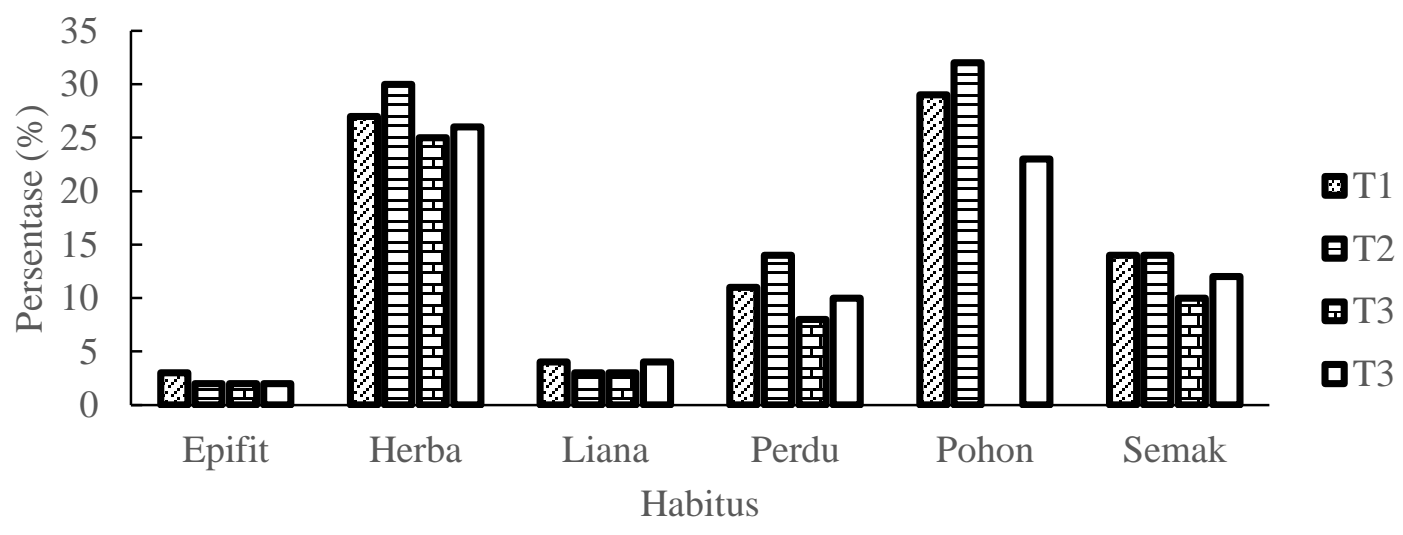

Gambar 2. Habitus Tumbuhan Obat Yang Ditemukan (Habitus of Kinds Medicinal Plants )

Keterangan : T1 = Hutan Tembawang Semajau, T2 = Hutan Tembawang Tebanan, T3 = Hutan Tembawang Sebayur, T4 = Hutan Tembawang Koling.

Dari Gambar diatas dapat dilihat bahwa pada T1 dan T2 pohon lebih banyak ditanami oleh masyarakat sekitar, karena dipercaya lebih banyak memberi manfaat pada kehidupan mereka, sedangkan rendahnya tumbuhan obat dalam bentuk tumbuhan efifit diduga dikarenakan tumbuhan efifit umumnya hanya dianggap sebagai gulma. Sedangkan pada T3 dan T4 herba lebih banyak ditemukan, karena habitus herba lebih mudah tumbuh diberbagai habitat. Adapun habitus yang dimanfaatkan oleh empat orang responden kunci serta masyarakat RW 2 dan masyarakat RW 9 dapat dilihat pada Gambar 3 dibawah ini.

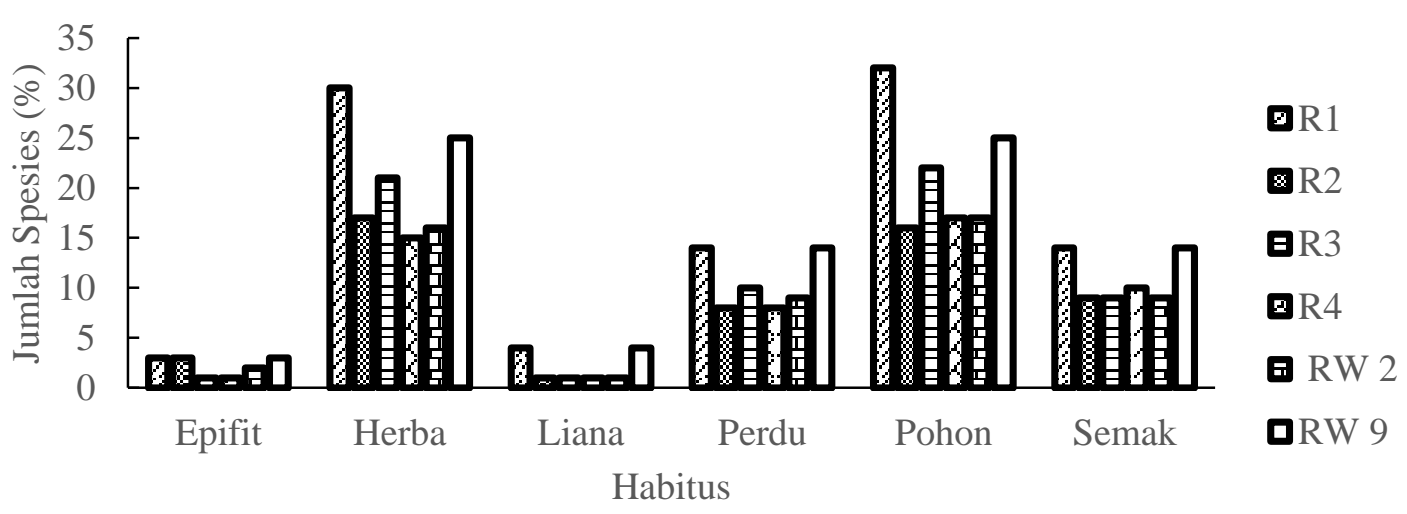

Gambar 3. Persentase Pemanfaatan Tumbuhan Obat Berdasarkan Habitus (Medicinal Plant Utilization Percentage Based On Habitus)

Banyaknya habitus tingkat pohon yang dimanfaatkan oleh R1 (32\%), R3 (22\%), R4 (17\%) serta masyarakat pada RW 2 (17\%) dan RW 9 (25\%) Kelurahan
Beringin. Penelitian ini sesuai dengan penelitian Syah et al.(2014) Di Dusun Nekbare Kabupaten Bengkayang, yang mengungkapkan bahwa banyaknya 
masyarakat memanfaatkan habitus tingkat pohon dikarenakan banyaknya bagian dari pohon mulai akar, batang, buah, bunga, daun, dan kulit batang dapat digunakan sebagai obat misalnya mengkudu (M.citrifolia). Akan tetapi berbeda dengan R2, beliau lebih banyak memanfaatkan habitus tingkat herba (17\%) dikarenakan habitus tingkat herba lebih mudah ditemukan karena mudah tumbuh di berbagai habitat, misalnya tumbuhan bandotan (A.conyzoides) selain ditanami tumbuhan tersebut juga biasanya tumbuh secara alami, hal ini sesuai dengan penelitian Albertus et al. (2015) yang menemukan bahwa banyaknya masyarakat di Kecamatan Tayan Hulu Kabupaten Sanggau menggunakan habitus herba dikarenakan lebih mudah tumbuh di berbagai habitat sehingga lebih mudah didapat dibanding habitus lainnya.

\section{Bagian Tumbuhan Obat Yang Dimanfaatkan}

Bagian tumbuhan obat yang paling banyak dimanfaatkan oleh empat orang responden kunci serta masyarakat RW 2 dan RW 9 tersebut adalah bagian daun yaitu, R1 47 spesies (47\%), R2 29 spesies (29\%), R3 30 spesies (30\%), R4 26 spesies (26\%), masyarakat RW 230 spesies (30\%), dan 42 spesies (42\%) yang dimanfaatkan oleh masyarakat RW 9. Dan yang paling sedikit adalah bagian umbi. Untuk Lebih jelasnya dapat dilihat pada Gambar 5.

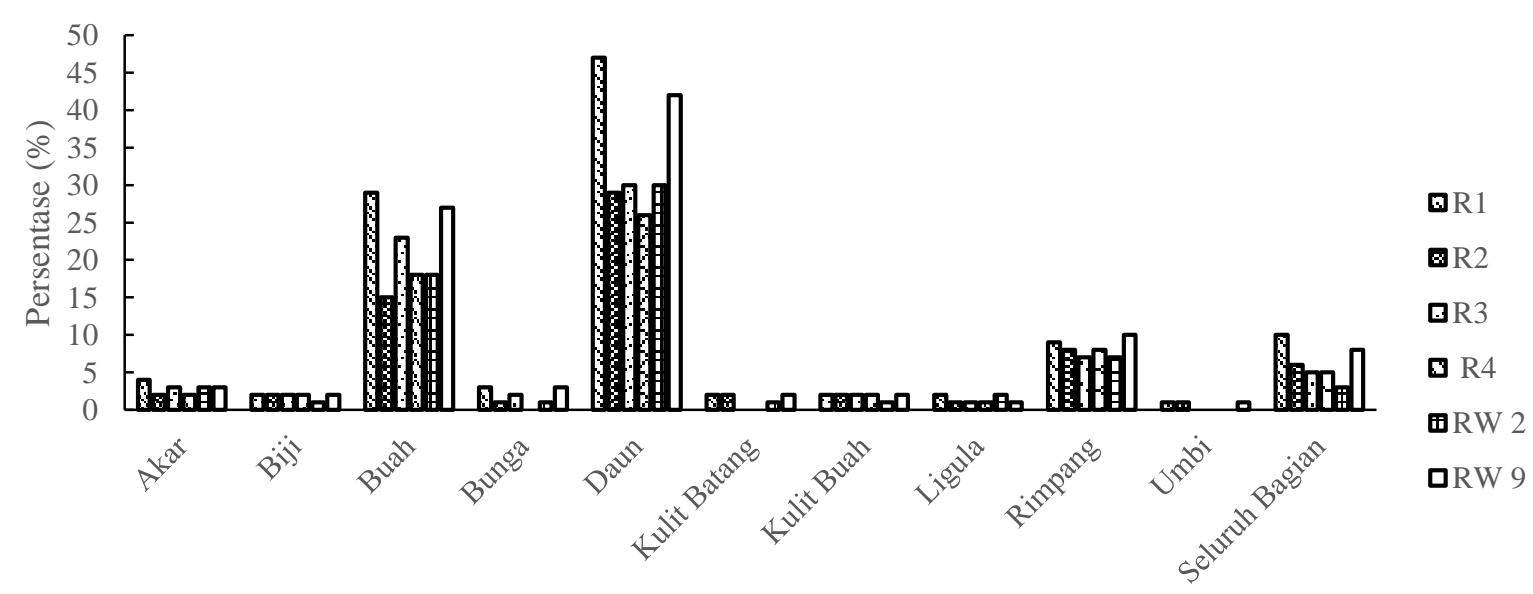

Bagian Tumbuhan Yang Dimanfaatkan

Gambar 5. Diagram Persentase Pemanfaatan Tumbuhan Obat Berdasarkan Bagian Tumbuhan (The Percentage Of Medicinal Plants Utilization Based On Plant Parts)

Keterangan : R1 = Responden Kunci 1, R2 = Responden Kunci 2, R3 = Responden Kunci 3, R4 = Responden Kunci 4. RW 2 = Masyarakat pada RW 2, RW 9 = Masyarakat pada RW 9

Bagian daun lebih banyak dimanfaatkan oleh seluruh responden kunci serta masyarakat umum pada RW 2 dan RW 9 Kelurahan Beringin dibandingkan bagian lainnya, misalnya daun cangkok
Manis (S. androgynus) untuk melancarkan ASI, kemudian gelinggang $\quad(C$. alata $)$ gatal-gatal pada kulit, jambu cacing (P.guajava) yang dimanfaatkan sebagai obat pelancar $\mathrm{BAB}$, kemunting $(M$. 
candidu) untuk menyembuhkan luka dan diabetes. Penelitian ini sejalan dengan penelitian Fakhrozi et al. (2009), yang mengungkapkan bahwa banyaknya masyarakat memanfaatkan daun sebagai obat karna mudah diperoleh dari pada bagian lainnya seperti batang, rimpang, bunga, buah maupun umbi. Daun merupakan organ tumbuhan yang selalu tersedia pada tumbuhan. Jika dilihat dari segi konservasi pengambilan daun tidak mengganggu dalam pelestarian tumbuhan.

\section{Cara Pengolahan Tumbuhan Obat}

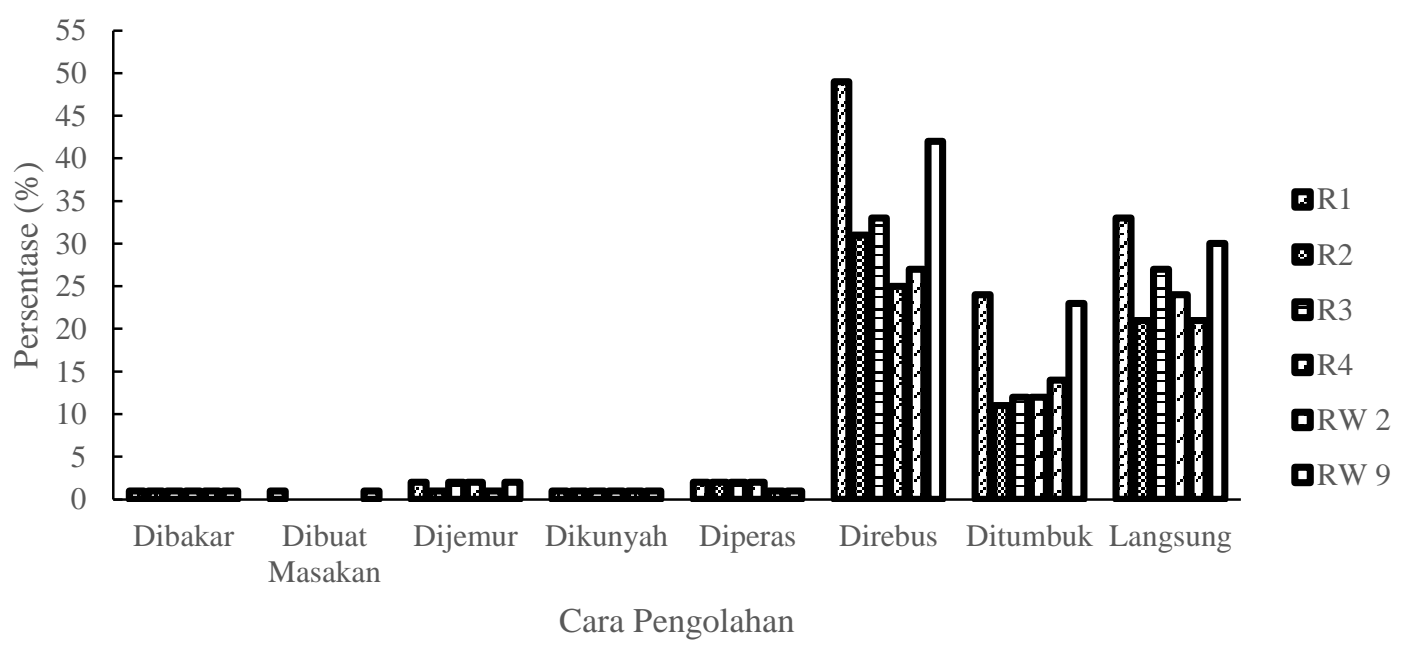

Pada penelitian ini berdasarkan hasil wawancara pada empat orang responden kunci serta masyarakat pada RW 2 dan RW 9 , pengolahan tumbuhan obat dengan cara direbus lebih banyak digunakan yaitu, R1 49 spesies (49\%), R2 31 spesies (31\%),R3 33 spesies (33\%), R4 25 spesies (25\%), RW 227 spesies (27\%), dan RW 942 spesies (42\%). Sedangkan pengolahan yang paling sedikit dilakukan adalah dengan cara dibakar dan dikunyah masing-masing sebanyak 1 spesies (1\%) saja. Untuk lebih jelasnya dapat dilihat pada Gambar 6.

Gambar 6. Diagram Persentase Pemanfaatan Tumbuhan Obat Berdasarkan Cara pengolahan (Utilization of Plant Medicine diagrams Percentage Based Processing Method)

Keterangan : R1 = Responden Kunci 1, R2 = Responden Kunci 2, R3 = Responden Kunci 3, R4 = Responden Kunci 4. RW 2 = Masyarakat pad RW 2, RW 9 = Masyarakat pada RW 9

Pengolahan tumbuhan obat oleh Masyarakat Kelurahan Beringin masih sangat sederhana yaitu dengan cara direbus lebih banyak dilakukan dibandingkan dengan cara dibakar dan dibuat masakan. Penelitian ini sesuai dengan penelitian Efermila et al. (2015) yang menemukan bahwa masyarakat di Kecamatan Mandor Kabupaten Landak lebih banyak mengolah tumbuhan obat dengan cara direbus, hal ini dikarenakan pengolahan dengan cara direbus dapat melarutkan semua zat berkhasiat yang terkandung pada tumbuhan obat yang ke dalam air rebusan tersebut

\section{Tumbuhan Obat Berdasarkan Cara Penggunaan \\ Penggunaan dengan cara oral (makan dan minum) ternyata lebih banyak dilakukan oleh seluruh}


responden Kelurahan Beringin yaitu, R1 sebanyak 74 spesies (74\%), R2 49 spesies (49\%), R3 58 spesies (58\%),R4 sebanyak 45 spesies (45\%). RW 247 spesies (47\%), dan 68 spesies (68\%) oleh RW 9. Untuk lebih jelasnya dapat dilihat pada Gambar 7.

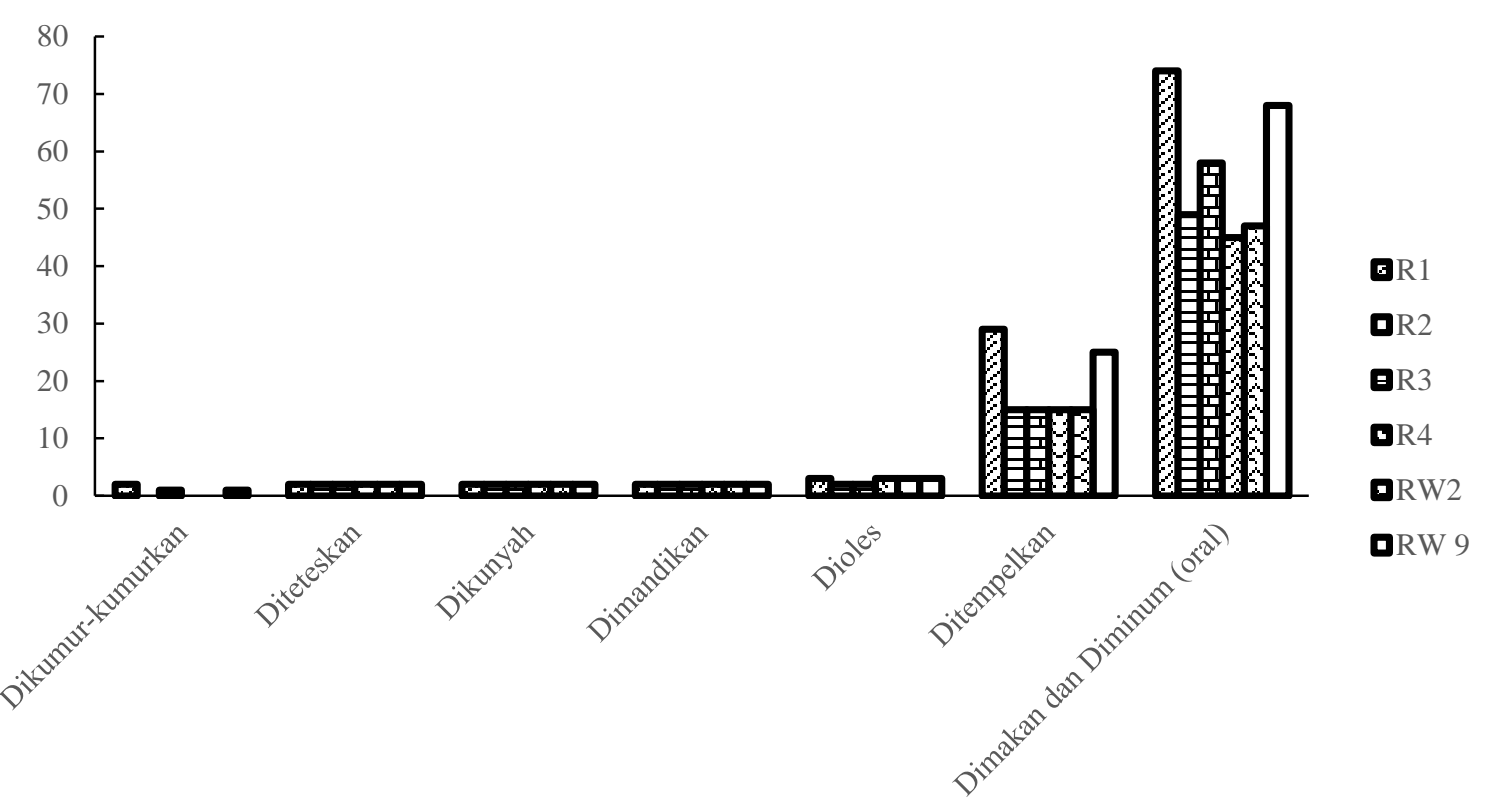

Gambar 8. Diagram Persentase Pemanfaatan Tumbuhan obat Berdasarkan Cara pengunaan (Utilization Based Medicinal Plants Administration Method)

Dari Gambar diatas dapat dilihat pemanfaatan tumbuhan obat dengan cara dimakan dan diminum (oral) lebih banyak dilakukan oleh masyarakat Kelurahan Beringin dibandingkan cara lainnya. Penelitian ini sesuai dengan Haryono et.al (2014) yang menemukan masyarakat di Desa Mengkiang Kabupaten Sanggau lebih banyak memanfaatkan tumbuhan obat dengan cara dimakan dan diminum (oral) karna diduga lebih cepat bereaksi dibandingkan dengan cara lainnya.

\section{Kesimpulan.}

Berdasarkan hasil penelitian terhadap jenis tumbuhan obat yang ada dihutan tembawang Lingkungan Semajau dan pemanfaatannya oleh masyarakat di RW 2 dan RW 9 Kelurahan Beringin Kabupaten Sanggau Kecamatan Kapuas, dapat disimpulkan sebagai berikut :

1. Tumbuhan obat yang dimanfaatkan oleh empat orang responden kunci dan ditemukan di empat hutan tembawang Lingkungan Semajau, berjumlah total 100 spesies yang terdistribusi dalam 55 famili. Hutan tembawang Tebanan merupakan hutan tembawang yang paling banyak memiliki jenis tumbuhan obat, yaitu sebanyak 96 spesies (96\%)

2. Pemanfaat tumbuhan obat terbanyak adalah Responden kunci satu (R1) yaitu sebanyak 96 spesies (96\%).

3. Famili Zingiberaceae lebih banyak ditemukan dari keempat hutan 
tembawang lingkungan semajau yaitu 7 spesies (7\%), dan famili yang paling banyak dimanfaatkan oleh responden kunci dan responden umum adalah famili Zingiberaceae yaitu sebanyak 7 spesies (7\%) oleh R1 dan R2, 6 spesies (6\%) oleh R3 dan R4, 5 spesies $(5 \%)$ oleh masyarakat RW 2, dan 7 spesies $(7 \%)$ oleh masyarakat RW 9.

4. Habitus yang paling banyak ditemukan pada T1 dan T2 yaitu habitus pohon sebanyak 29 spesies (29\%) dan 32 spesies (32\%), sedangkan pada T3 dan T4 ternyata habitus herba yang lebih banyak ditemukan yaitu 25 spesies (25\%) dan 26 spesies (26\%).

5. Daun merupakan bagian tumbuhan yang paling banyak dimanfaatkan oleh responden kunci dan responden umum sebagai obat, yaitu R1 memanfaatkan sebanyak 47 spesies (47\%), R2 sebanyak 29 spesies (29\%), R3 sebanyak 30 spesies (30\%), dan R4 sebanyak 26 spesies (26\%). Kemudian pada masyarakat umum pada RW 2 memanfaatkan daun sebanyak 30 spesies (30\%), dan sebanyak 42 spesies (42\%) oleh masyarakat RW 9.

6. Pengolahan dengan cara direbus lebih banyak dilakukan oleh seluruh responden kunci maupun responden umum yaitu, sebanyak 49 spesies (49\%) oleh R1, 31 spesies (31\%) oleh R2, 33 spesies (33\%) oleh R3, dan 25 spesies (25\%) oleh R4. Kemudian pada masyarakat umum di RW 2 sebanyak 27 spesies (27\%), dan RW 9 sebanyak 42 spesies (42\%).

7. Penggunaan dengan cara oral (makan dan minum) ternyata lebih banyak dilakukan oleh seluruh responden kunci dan responden umum yaitu, R1 sebanyak 74 spesies (74\%), R2 sebanyak 49 spesies (49\%), R3 sebanyak 58 spesies (58\%), R4 sebanyak 45 spesies (45\%). RW 2 sebanyak 47 spesies (47\%), dan sebanyak 68 spesies $(68 \%)$ oleh RW 9.

\section{Saran}

Sebaiknya masyarakat di Kelurahan Beringin Kabupaten Sanggau Kecamatan Kapuas perlu membudidayakan tumbuhan obat terutama di perkarangan rumah agar tumbuhan obat dengan mudah diperoleh. Perlu adanya dokumentasi tentang jenisjenis tumbuhan obat dari cara pemanfaatannya, agar pengetahuan tentang pemanfaatan tumbuhan obat tetap terjaga, karena secara umum masyarakat masih menyampaikannya secara lisan sehingga bukan mustahil jika hal itu dibiarkan pengetahuan tentang pemanfaatan tumbuhan obat akan terkikis seiring berjalannya waktu. Perlu penyuluhan lebih lanjut untuk masyarakat pada Kelurahan Beringin Kabupaten Sanggau Kecamatan Kapuas agar mendapatkan informasi tentang tumbuhan obat lebih dalam lagi,

\section{DAFTAR PUSTAKA}

Albertus, Dewantara I, Herawatiningsih R. 2015. Jenis Dan Potensi Tumbuhan Obat Pada Kawasan Hutan Adat Gunung Semarong 
Kecamatan Tayan Hulu Kabupaten Sanggau. Jurnal Hutan Lestari. 3(3):446-455

Bodeker G. 2000. Partnership Against Aids : Incorporating the Traditional Sector For Prevention And Management (pp 87-90) In Bell $\mathrm{k}$ (ed), Aids in the Commonwealth. London : Kensington Press.

Efremila, Wardenaar E, Sisillia L. 2015. Studi Etnobotani Tumbuhan Obat Oleh Etnis Suku Dayak Di Desa Kayu Tanam Kecamatan Mandor Kabupaten Landak. Jurnal Hutan Lestari. 3(2):234-246.

Haryono D, Wardenaar E, Yusro F. 2014. Kajian Etnobotani Tumbuhan Obat Di Desa Mengkiang Kecamatan Sanggau Kapuas Kabupaten Sanggau. Jurnal Hutan Lestari 3(2):427-434

ITTO. 2011. Potensi tengkawang di lahan masyarakat lokal Kalimantan Barat. Forestry Research and Development Agency (FORDA) Ministry of Forestry.

Nurhaida, Usman FH, Tavita GE. 2015. Studi Etnobotani Tumbuhan Obat Di Dusun Kelapuk Kecamatan Tanah Pinoh Barat Kabupaten Melawi. Jurnal Hutan Lestari 3(4):526-537.

Palupi NP. 2013. Kearifan Lokal Tanaman Obat Masyarakat Dayak Agabang di Kabupaten Nunukan Kalimantan Timur. Jurnal Agrifor. 8(1):83-95.

Sardana A, Hernawati J, Dharma NGGY, Nugroho AE, Aliyah N. 2011. Potret Provinsi Kalimantan Barat. Kementrian Kehutanan Direktorat Jendral Planologi Kehutanan Balai Pemantapan
Kawasan Hutan Wilayah III Pontianak (ID): Pontianak.

Sari A, Linda R, Lovadi I. 2015. Kajian Etnobotani Tumbuhan Obat Pada Masyarakat Dusun Semoncol Kecamatan Balai Kabupaten Sanggau. Jurnal Protobiont $4(2): 1-8$

Sumarhani dan Titik Kalima. 2015. Struktur Dan Komposisi Vegetasi Agroforestri Tembawang Di Kabupaten Sanggau Kalimantan Barat. Jurnal Pros Sem Nas Masy Biodiv Indon. 1(5):1099-1104.

Syah J, H. Usman F, Yusro F. 2014. Etnobotani Tumbuhan Obat Yang Dimanfaatkan Masyarakat Dusun Nekbare Kabupaten Bengkayang. Jurnal Hutan Lestari. 2(2): 419426

Warida S, Brahmana EM, Mubarrak J. 2017. Identifikasi Tumbuhan Obat Yang Ada Di Kecamatan Rambah Hilir Kabupaten Rokan Hulu Propinsi Riau. Jurnal Ilmiah Mahasiswa FKIP Prodi Biologi 3(1). 1-6 